\title{
Ribosome biogenesis dysfunction leads to p53-mediated apoptosis and goblet cell differentiation of mouse intestinal stem/progenitor cells
}

\author{
A Stedman ${ }^{1,2}$, S Beck-Cormier ${ }^{1,2,7}$, M Le Bouteiller ${ }^{1,2,8}$, A Raveux ${ }^{1,2}$, S Vandormael-Pournin ${ }^{1,2}$, S Coqueran ${ }^{1,2}$, V Lejour ${ }^{3,4,5}$, \\ L Jarzebowski $^{1,2}$, F Toledo ${ }^{3,4,5}$, S Robine ${ }^{6}$ and M Cohen-Tannoudji*, ${ }^{1,2}$
}

Ribosome biogenesis is an essential cellular process. Its impairment is associated with developmental defects and increased risk of cancer. The in vivo cellular responses to defective ribosome biogenesis and the underlying molecular mechanisms are still incompletely understood. In particular, the consequences of impaired ribosome biogenesis within the intestinal epithelium in mammals have not been investigated so far. Here we adopted a genetic approach to investigate the role of Notchless (NLE), an essential actor of ribosome biogenesis, in the adult mouse intestinal lineage. Nle deficiency led to defects in the synthesis of large ribosomal subunit in crypts cells and resulted in the rapid elimination of intestinal stem cells and progenitors through distinct types of cellular responses, including apoptosis, cell cycle arrest and biased differentiation toward the goblet cell lineage. Similar observations were made using the rRNA transcription inhibitor CX-5461 on intestinal organoids culture. Importantly, we found that p53 activation was responsible for most of the cellular responses observed, including differentiation toward the goblet cell lineage. Moreover, we identify the goblet cell-specific marker Muc2 as a direct transcriptional target of p53. Nle-deficient ISCs and progenitors disappearance persisted in the absence of $p 53$, underlying the existence of p53-independent cellular responses following defective ribosome biogenesis. Our data indicate that NLE is a crucial factor for intestinal homeostasis and provide new insights into how perturbations of ribosome biogenesis impact on cell fate decisions within the intestinal epithelium.

Cell Death and Differentiation (2015) 22, 1865-1876; doi:10.1038/cdd.2015.57; published online 12 June 2015

Construction of ribosomes in eukaryotes is a highly complex process. Upon transcription in the nucleolus, the pre-rRNA undergoes a series of cleavages and modifications while being assembled into ribosomal preparticles upon hierarchical addition of ribosomal proteins. ${ }^{1}$ In yeast, $\approx 200$ assembly factors and several small nucleolar RNAs have been shown to participate to these processes. In higher eukaryotes, though the core components have been conserved, differences were reported $^{2-5}$ suggesting that ribosome biogenesis has become more complex with evolution.

A specific pathway dedicated to the surveillance of ribosome biogenesis was identified originally in mammalian cells. Inhibition of RNA polymerase I activity, or deficiencies in factors required in ribosome biogenesis, was shown to trigger the binding of a $5 S$ rRNA/RPL11/RPL5 inhibitory complex to the MDM2 ubiquitin ligase, thereby preventing MDM2mediated p53 degradation. ${ }^{6-8}$ In human, pathologies caused by ribosome biogenesis dysfunction are called ribosomopathies and represent a set of clinically distinct diseases presenting with tissue-specific developmental defects and increased risk of cancer., ${ }^{9,10}$ Studies on cellular and animal models suggest that unscheduled upregulation of p53 may account for many clinical symptoms associated with ribosomopathies. ${ }^{11-16}$ There are now evidences that ribosome biogenesis dysfunction also triggers p53-independent mechanisms. ${ }^{17-19}$ Because bone marrow defects is a frequent clinical manifestation of ribosomopathies, most studies focused on the hematopoietic tissue and less is known about the impact of ribosome biogenesis dysfunction in other organs.

Notchless (Nle) encodes a WD40 repeats-containing protein highly conserved in eukaryotes. Its ortholog in yeast, Rsa4, was shown to be essential for the late step of maturation and subsequent export of the 605 particle. ${ }^{20-22}$ We recently showed that Nle role in the maturation of the large ribosomal subunit is conserved in mouse and that Nle is required for the maintenance of hematopoietic stem cells. ${ }^{23}$ During the course of this study, we noticed that the gut was also sensitive to Nle

\footnotetext{
${ }^{1}$ Mouse Functional Genetics, Department of Developmental \& Stem Cell Biology, Institut Pasteur, 25 rue du docteur Roux, Paris, France; ${ }^{2} \mathrm{CNRS}$ URA 2578, Paris, France; ${ }^{3}$ Genetics of Tumor Suppression, Equipe Labellisée Ligue Nationale Contre le Cancer, Institut Curie, Centre de recherche, Paris, France; ${ }^{4} U P M C$ University Paris 06, Paris, France; ${ }^{5}$ CNRS UMR 3244, Paris, France and ${ }^{6}$ Unité Mixte de Recherche 144, Centre National de la Recherche Scientifique, Institut Curie, Paris, France

*Corresponding author: M Cohen-Tannoudji, Mouse Functional Genetics, Department of Developmental \& Stem Cell Biology, Institut Pasteur, 25 rue du docteur Roux, F-75015 Paris, France. Tel: +33 1456884 86; Fax: +33 1456886 34; E-mail: m-cohen@pasteur.fr

${ }^{7}$ Current address: Institut National de la Sante et de la recherche Medicale, U791, LIOAD, STEP group 'Skeletal Tissue Engineering and Physiopathology', Université de Nantes, UFR Odontologie, F-44042 Nantes, France.

${ }^{8}$ Current address: Biotech Research and Innovation Center, University of Copenhagen, DK-2200 Copenhagen N, Denmark.

Abbreviations: BrdU, Bromo-deoxyuridine; CBC, crypt base columnar; CKO, conditionnal Knock-out; GFP, green fluorescent protein; IRES, internal ribosome entry site; Its, internal spacer; Nle, Notchless; PBS, phosphate-buffered saline; PCR, polymerase chain reaction; qPCR, quantitative polymerase chain reaction; PFA, paraformaldehyde; SC, stem cell; ISC, intestinal stem cell; TA, transit-amplifying; RE, response element

Received 28.8.14; revised 31.3.15; accepted 13.4.15; Edited by M Oren; published online 12.6.15
} 
deletion. Here we performed the conditional inactivation of Nle in the intestinal epithelium and showed that Nle-dependent large ribosomal subunit biogenesis is required for the maintenance of intestinal stem cells (ISCs) and progenitors. Combining in vivo analyses with intestinal organoids culture, we demonstrate that defective ribosome biogenesis leads to p53-mediated removal of intestinal SCs and progenitors through several mechanisms including biased differentiation toward the goblet cell lineage. Finally, we show that p53independent responses are also at play in Nle mutant crypt cells.

\section{Results}

Nle is required in intestinal crypts. We previously showed that Nle is widely expressed in the mouse. ${ }^{24}$ To examine more precisely its pattern of expression in the adult small intestine, we performed RT-qPCR and western blot analyses on crypts and villi fractions. We found that both Nle mRNA and protein were enriched in crypts compared with villi (Figures 1a and b). To specifically delete Nle in the intestinal epithelium, we used the Villin-CreERT2 transgenic line. Control (Villin-CreERT2 ${ }^{\text {tg/O }} ; \mathrm{Nle}^{\text {flox/+ }}$ ) and NleVilcKO (VillinCreERT2 ${ }^{t g / O}$; Nle $e^{\text {flox/null) }}$ littermates were subjected to daily intraperitoneal tamoxifen injection and analyzed at various time points post last tamoxifen injection (p.i.) (Figure 1c). To monitor the conversion of the $\mathrm{Nl}^{\text {flox }}$ allele into the $\mathrm{Nle} e^{\mathrm{del}}$ allele, we performed genomic PCR targeting both alleles. We found that Cre-mediated recombination of the $N e^{f l o x}$ allele was efficient in crypts and villi from both Control and NleVilcKO mice (Figure 1d). Efficiency of deletion was confirmed by the marked decrease of NLE protein levels in NleVilcKO crypts and villi (Figure 1b). A small proportion of nonrecombined cells persisted in the epithelium at the end of the tamoxifen regimen as indicated by the presence of a faint $\mathrm{Nle}^{\text {flox }}$ signal in Control and NleVilcKO samples at day 1 p.i. (Figure 1d). Contrary to Controls that showed limited level of nonrecombined allele up to 60 days p.i. (Figure 1d), the $N / e^{\text {flox }}$ and $N e^{\text {del }}$ alleles were detected at equivalent level in NleVilcKO intestine at day 4 p.i. and the NIedel allele was no longer detectable at day 60 p.i. (Figure 1d). This indicates that Nle-deficient intestinal epithelium was rapidly and entirely replaced by Nle-proficient cells derived from ISCs that have escaped deletion.

Hematoxylin-eosin staining revealed that crypts, but not villi, were clearly affected following Nle deletion. At day 1 p.i., apoptotic bodies were present and many crypts exhibited a progressive degeneration phenotype in the following days (Figure 1e, arrowheads and arrows). At day 4 p.i., intestinal regeneration was readily visible, with the presence of abnormally big, hyperplastic crypts (Figure 1e, bracket). Consistent with the reappearance of Nle-proficient epithelium, normal histology was observed on sections of NleVilcKo intestines at later time points. Collectively, these data show

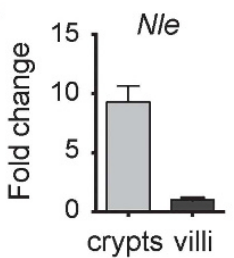

b

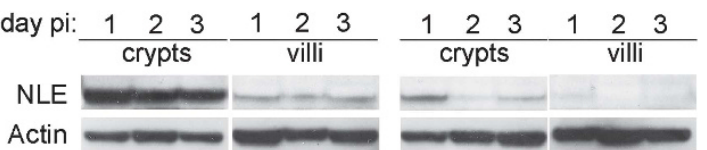

c

d Control NleVilcKO

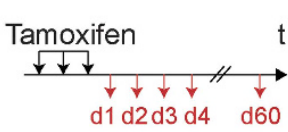

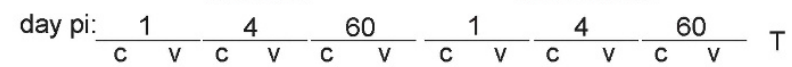
${ }_{\mathrm{flox}}^{\mathrm{del}}-------$

e Control d1 pi
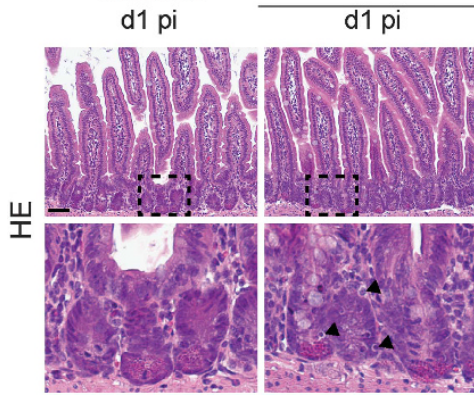

NleVilcKO

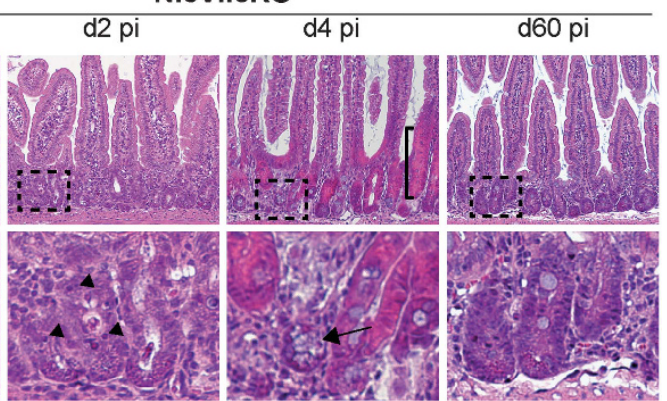

Figure $1 \mathrm{Nle}$ is required in intestinal crypts. (a) RT-qPCR analysis of Nle mRNA levels in crypts and villi. (b) Western blot for NLE and $\alpha$-Actin on crypts or villi enriched extracts from Control and NleVilcKO intestine. All extracts were run on the same gel. (c) Scheme of tamoxifen injection and analysis. (d) Detection of the nonrecombined (flox) and the recombined (del) Nle alleles by PCR performed on crypts (c) or villi (v) enriched DNA extracts from Control and NleVilcKO small intestine. Two bands of similar intensity are amplified from Nle ${ }^{\text {floxddel }}$ DNA (T). The wild-type Nle allele is not amplified in this reaction. (e) Hematoxylin-eosin staining of sections from Control and NleVilcKO small intestine. The second line shows magnified views of framed regions. Black arrowheads point to apoptotic bodies. Black bracket indicates a hyperplasic crypt. Black arrow shows a dying crypt. Scale bar, $50 \mu \mathrm{m}$ 
that Nle function is required for the maintenance of ISCs and crypt homeostasis.

Nle deletion impairs survival and proliferation of intestinal SC and progenitors. We observed a significant increase in Caspase 3-dependent apoptosis in NleVilcKO crypts at day 2 p.i. (Figures $2 a$ and b). Noticeably, apoptosis seemed to occur preferentially at the crypt base where stem cells and progenitors reside (Figure $2 \mathrm{a}$, data not shown). Increased apoptosis was accompanied by a decrease in the proliferation of intestinal progenitors at day 2 p.i., though some crypts, probably containing recombination escaper cells, retained a normal proliferation profile (Figure 2a, arrow, Figure 2c).

To investigate the early response of ISCs to Nle inactivation, we first examined the expression levels of ISCs markers by RT-qPCR. At day 1 p.i., the molecular signature of ISCs was partially deregulated since Bmi1 expression was increased, and Olfm4 expression was decreased while Lgr5 and Tert expression was unaffected. One day later, Olfm4 downregulation persisted and Bmi1 expression returned to levels similar to Control mice (Figure 2d). Such uncoupling between Lgr5 and Olfm4 expression was puzzling as Olfm4 was described as a robust marker of Lgr5-positive ISCs. ${ }^{25}$ To clarify this point, we first looked at Olfm4 expression by in situ hybridization. Most crypt bases were devoid of Olfm4 expression, and consisted of packed lysozyme-positive paneth cells (Figure $2 \mathrm{e}$ ) suggesting that crypt base columnar (CBC) stem cells were no longer present at the crypt bases in NleVilcKO mice. Introgression of the Lgr5 GFP-IRES-CreERT2 allele into Control and NleVilcKO mice confirmed the absence of GFP-positive CBC cells intermingled with paneth cells at the base of Nle mutant crypts (Supplementary Figure S1A, white bracket). In mutant crypts, strong GFP expression was observed in Olfm4-negative cells located above paneth cells and at positions normally occupied by progenitors suggesting

a

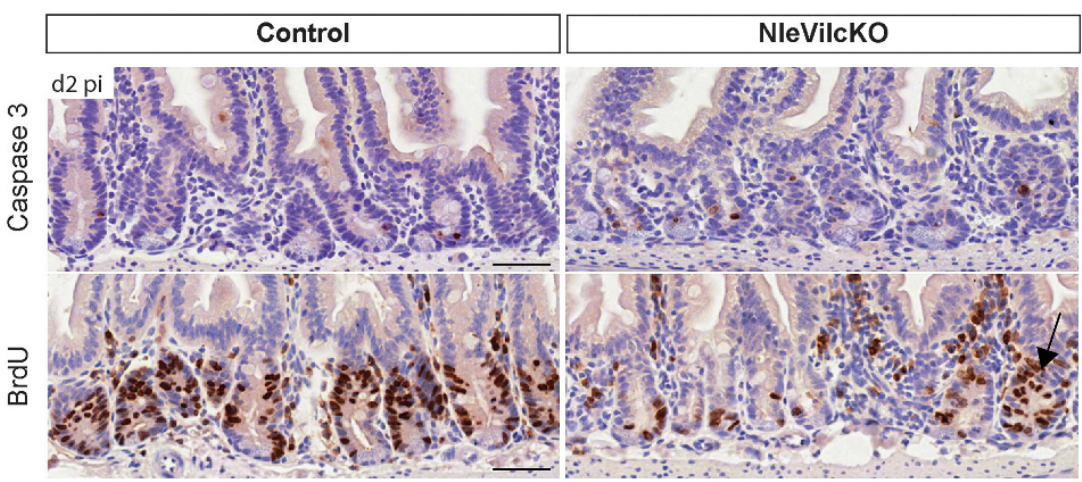

b

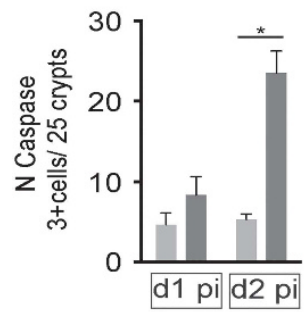

C

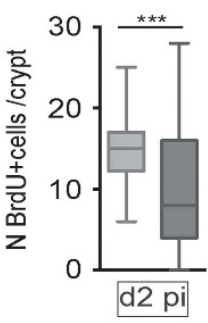

d

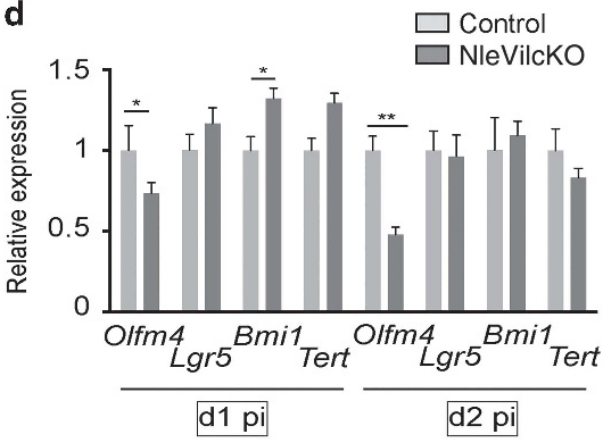

e

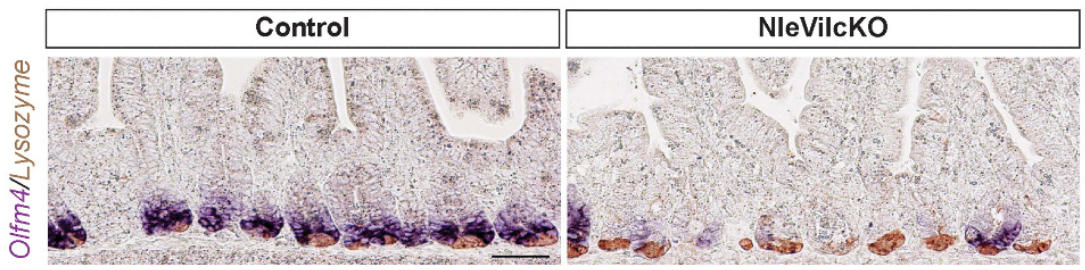

Figure 2 Nle deletion is detrimental for ISCs and progenitors. (a) Cleaved-Caspase 3 and BrdU immunostaining of intestinal sections from Control and NleVilcKO intestine at day 2 p.i. Rare crypts with normal proliferation profile (arrow) were observed. Scale bars, $50 \mu \mathrm{m}$. (b) Histogram showing the mean number ( \pm S.E.M.) of Caspase 3-positive cells per 25 crypts in Control and NleVilcKO small intestine. Twenty five traverse crypts were scored per mouse, $n=3$ for each genotype. ${ }^{*} P<0.05$, Mann-Whitney Wilcoxon test. (c) Box and whiskers plot showing the number of BrdU-positive cells per crypt in Control and mutant NleVilcKO mice. Twenty five traverse crypts were scored per mouse, $n=3$ for each genotype. ${ }^{* * *} P<0.001$ t-test. (d) RT-qPCR performed on mRNA from Control and NleVilcKO intestinal extracts. Graphs represent the mean fold changes \pm S.E.M. for transcripts enriched in ISCs. $n \geq 5$ for each genotype. ${ }^{*} P<0.05$ Mann-Whitney Wilcoxon test. (e) In situ hybridization for Olfm 4 mRNA (blue staining) combined with lysozyme immunostaining (brown staining) on intestinal sections from Control and NleVilcKO intestine. Scale bars, $50 \mu \mathrm{m}$ 
that either $\mathrm{CBC}$ stem cells have been displaced from their niche or mutant progenitors maintained high levels of Lgr5 expression (Supplementary Figure S1A, white bracket, Supplementary Figure S1B, arrow). Altogether, these data suggest that the ISC pool is rapidly compromised following NIe deletion.

We next tested the capacity of Nle-deficient crypts to form organoids in vitro. ${ }^{26}$ Cultures were established with crypts from Control and NleVilcKO mice $1 \mathrm{~h}$ following the last tamoxifen injection. Control crypts grew into organoids within 3 days of culture, and the vast majority had developed more than 3 buds after 6 days. In contrast, NleVilcKO crypts maintained as small nonbudding units and eventually died (Supplementary Figure S2) confirming that intestinal SC and progenitors are rapidly compromised following Nle deletion.

\begin{abstract}
Nle deletion increases differentiation toward the goblet cell lineage. We then analyzed the impact of Nle inactivation on the differentiation of the different intestinal cell types. NleVilcKO intestines did not present obvious changes in the size of the villi, suggesting that enterocytic differentiation was not altered. Both alcian blue coloration and MUC2 immunostaining revealed the presence of crypts harboring an excessive number of goblet cells in NleVilcKO intestines at day 3 p.i. (Figure $3 a$, arrows, Supplementary Figure S3A). In Control mice, crypts with more than five goblet cells were rare $(3 \%)$ and contained on average six goblet cells. Mutant crypts with numerous goblet cells were more frequent (11\%) and contained on average 12 goblet cells (Supplementary Figures S3A and B). Goblet cells were found all along the crypt axis, including at the crypt bottom (Figure $3 a$, asterisks). Altogether, these results suggest that Nle-deficient progenitors underwent premature differentiation. The other secretory cell lineages did not seem affected (Supplementary Figure S3C). Consistent with these results, we measured by RT-qPCR a moderate but significant upregulation of the goblet cell marker Muc2 in NleVilcKO intestines, whereas Chromogra$\operatorname{nin} A$ and Lysozyme mRNA levels were unchanged (Figure $3 b$ ). We found that the local increase in goblet cell number was preceded by the upregulation of Atoh1, a key regulator of secretory cell lineage commitment, ${ }^{27}$ and of Spdef, which is required downstream of Atoh1 for goblet cell terminal maturation ${ }^{28}$ (Figure 3c). Hes1 expression was unchanged, confirming that the absorptive lineage was not affected by Nle loss of function (Figure 3c).

Altogether, these results demonstrate that Nle deficiency rapidly compromises crypts homeostasis by triggering apoptosis, cell cycle exit and premature differentiation into goblet cell lineage of intestinal SCs and progenitors.
\end{abstract}

Biogenesis of the large ribosomal subunit is affected in Nle mutant crypts. To verify that Nle deficiency affected biogenesis of the large ribosomal subunit (60S) in the mouse intestine, we first performed fluorescent in situ hybridization (FISH) on small intestine sections. Its 1 and its2 probes were used to evaluate the levels of nucleolar rRNA intermediates of, respectively, the small and large ribosomal subunits (Figure 4a). In Control intestines, although nascent rRNA intermediates were detected in most cells, enriched expression was observed in epithelial cells of the crypts and of the lower part of the villi (Figure 4b). These cells showed a clear upregulation of its 2 signal in NleVilcKO mice at day 1 p.i. (Figure 4b). Its1 signal was also increased, though to a lesser extent. Increased level of nucleolar rRNA intermediates was also evidenced when performing $\mathrm{FISH}$ with a $28 \mathrm{~S}$ probe (Supplementary Figure S4), and was further confirmed by RT-qPCR on total intestine RNA extracts (Figure 4c). We next monitored the effect of Nle deletion on the processing of the different rRNAs intermediates by performing a northern blot experiment on RNAs extracted from Control and NleVilcKO crypts at day 1 p.i. (Figure 4d). Consistent with the role of Nle in large subunit maturation, specific accumulation of rRNA precursors of the large subunit was observed in NleVilcKO crypts (Figure 4d, arrows).

Levels of $18 \mathrm{~S}$ and $28 \mathrm{~S}$ mature rRNAs were not altered in NleVilcKO crypts at day 1 p.i. (Figure $4 \mathrm{c}$ and Supplementary Figure S4) suggesting that large subunit biogenesis defects in Nle-deficient progenitors did not cause a rapid reduction in ribosome content. To verify this point, crypt protein extracts were prepared from Control and NleVilcKO mice 10 min after puromycin injection and analyzed by immunoblotting using anti-puromycin monoclonal antibody. Puromycin enters cells and is covalently incorporated into nascent polypeptides allowing the quantification of actively translating ribosomes. ${ }^{29}$ At day 2 p.i., when the phenotype is the most severe, no significant change in the quantity of puromycylated nascent chains was detected in NleVilcKO crypts compared with Control (Figure $4 \mathrm{e}$ ), suggesting that protein translation was not altered at this early time point after Nle deletion.

Defects in ribosome biogenesis trigger p53 activation in ISCs and progenitors. A dedicated surveillance pathway tightly links the activity of ribosome biogenesis to p53 levels. We therefore analyzed p53 protein levels in Nle-deficient intestine by immunostaining and western blot analysis. We found that p53 was stabilized in NleVilcKO crypts as early as day 1 p.i. (Figures $5 a$ and c). At this time point, nuclear p53 protein could be detected in CBC stem cells, recognizable by their shape and location at the crypt base (Figure $5 b$ ). Noticeably, p53 activation was detected neither in villi nor in paneth cells. Consistent with p53 activation, we measured a significant increased expression of several p53 direct transcriptional targets such as the cell cycle inhibitor p21 (Figures $5 c$ and d), and the proapoptotic genes Bax, Pidd and Noxa (Figure 5d).

To test whether p53 pathway activation was a general feature of ISCs and progenitors response to ribosome biogenesis defects, we treated intestinal organoids with CX-5461, a selective inhibitor of RNA polymerase I-driven rRNA transcription. ${ }^{30}$ Incubation of organoids with $1 \mu \mathrm{M}$ CX-5461 resulted in a rapid reduction in rRNA precursors levels (Figure 6a). After 1 day of treatment, buds size appeared reduced compared with vehicle-treated control organoids (Figure 6b), and after 2 days most treated organoids started to degenerate (not shown). At day 1, CX-5461 treatment resulted in increased mRNA levels of several p53 target genes (Figure 6c) as well as variations in expression of markers of SCs, progenitors and differentiated cells (Figures 6d-f) suggesting that inhibition of rRNA transcription causes p53 activation and affects survival and differentiation 
a
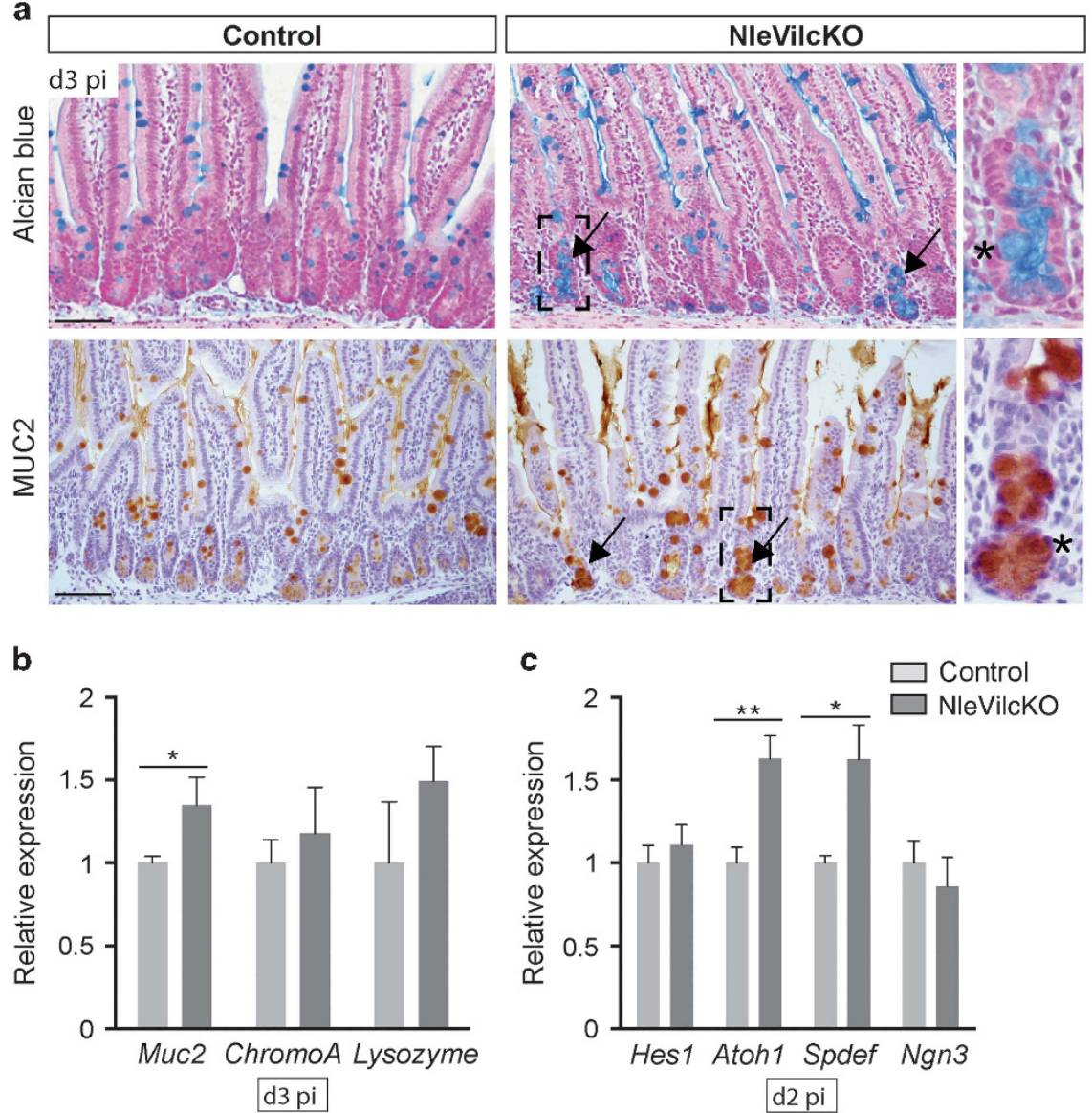

Figure 3 Nle deletion leads to biased differentiation toward the goblet lineage. (a) Alcian blue staining and MUC2 immunostaining on intestinal sections from Control and $\mathrm{NleVilcKO}$ intestine. Black arrows show crypts with elevated number of goblet cells. Third row shows magnified views of framed regions. Asterisks indicate goblet cells ectopically located in the stem cell zone. Scale bars, $50 \mu \mathrm{m}$. (b and $\mathbf{c}$ ) RT-qPCR performed on mRNA from Control and NleVilcKO intestinal extracts. Graphs represent the mean fold changes \pm S.E.M. for transcripts representative of cells from the different secretory lineages (b) or intestinal progenitors (c). $n \geq 4$ for each genotype. ${ }^{*} P<0.05$ Mann-Whitney Wilcoxon test

of intestinal SC and progenitors ex vivo. Although the experimental conditions differed, CX-5461-treated organoids and intestinal epithelium of NleVilcKO mice shared striking similarities including uncoupling in the expression of Olfm4 and Lgr5 SC markers and upregulation of Muc2 goblet cell marker. Interestingly, such variations were not observed when p53-deficient organoids were treated with CX-5461 (Figures $6 \mathrm{~g}$ and $\mathrm{k}$ ).

Altogether, these results strongly suggest that defects in large ribosomal subunit biogenesis caused by Nle deficiency activate a potent p53 response in intestinal SCs and progenitors.

p53 drives the elimination of intestinal SCs and progenitors by cell cycle arrest, apoptosis and directed differentiation toward the goblet cell lineage. To evaluate the contribution of $p 53$ in the phenotype of Nle mutant crypts, we crossed NleVilcKO mice with $p 53^{-1-}$ mice. NleVilcKO; p53KO double mutants (VilCreERT2tg/o; Nle ${ }^{\text {flox/null; }} p 53^{-1}$ ) were compared with NleVilcKO; p53+/- (Villin-CreERT2tg/o; $\mathrm{Nle}^{\text {flox/null }} ; p 53^{+/-}$) and Control; p53KO (Villin-CreERT2 $2^{\text {tg/o }}$; $\mathrm{Nl}^{\text {flox/++}}$; $p 53^{-/}$) littermates, as well as to wild-type p53 Controls from the previous cross (Villin-CreERT2tg/o;
$\left.\mathrm{Nl}^{\text {flox/++}} ; p 53^{+/+}\right)$. Intestinal phenotype of NleVilcKO; p53+/mice was similar to that of NleVilcKO mice, including decreased Olfm4 expression, reduced proliferation and local increase in goblet cell number in the crypts (Figure 7a). Strikingly, both the expression of Olfm4 at the crypt base and proliferation in the transit-amplifying compartment were restored in NleVilcKO; p53KO crypts, showing that Nle-deficient ISCs and progenitors were elimimated via a p53-dependent mechanism (Figures 7a and c). In addition, NleVilcKO; p53KO crypts exhibited a rescued pattern of goblet cell differentiation (Figure 7a). Consistently, Muc2 expression was significantly reduced in NleVilcKO; p53KO mice compared with NleVilcKO; p53+/(Figure $7 d$ ). We next used in silico analysis ${ }^{31}$ to identify putative p53 response elements (REs) associated with goblet cellspecific genes. Interestingly, two partially overlapping p53 REs with high scores were found within an intronic sequence of the Muc2 gene (Figures $7 \mathrm{e}$ and $\mathrm{f}$ ). When this intronic sequence was cloned upstream of a luciferase reporter gene, a strong induction was observed upon cotransfection with a p53 expression vector into p53-deficient fibroblasts (Figure 7g). Either deletion of the two REs or use of an expression vector encoding a p53 variant lacking transactivation activity (p53R270H) abolished luciferase reporter induction (Figure 7g). 

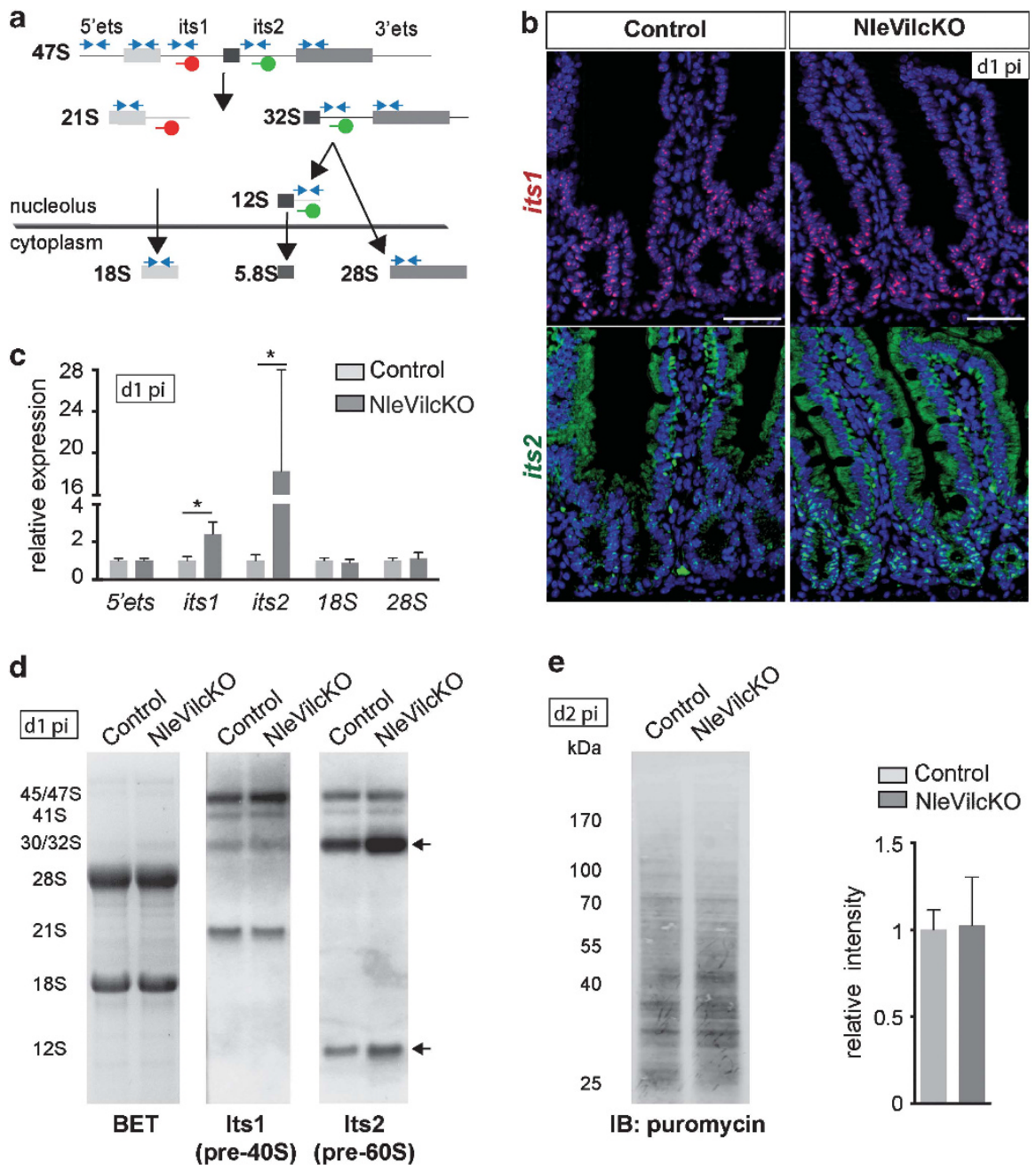

Figure 4 Ribosome biogenesis is impaired in Nle mutant crypts. (a) Simplified diagram illustrating the main steps of ribosome biogenesis in eukaryotic cells. Blue arrows represent the primers used to measure the levels of ribosomal RNAs by RT-qPCR. FISH probes used to detect its1 (red) and its2 (green) sequences from precursors of the small and large ribosomal subunits, respectively, are indicated. (b) FISH for its1 (red) or its2 (green) on intestinal sections from Control and NleVilcKO intestine. Scale bars, $20 \mu \mathrm{m}$. (c) RT-qPCR performed on mRNA from Control and NleVilcKO intestinal extracts. Graphs represent the mean fold changes \pm S.E.M. for the different amplicons. $n=3$ for each genotype. ${ }^{*} P<0.05$ Mann-Whitney Wilcoxon test. (d) Northern blot of RNAs from Control and NleVilcKO crypts at day 1. In the left panel, BET coloration shows the $28 \mathrm{~S}$ and $18 \mathrm{~S}$ rRNAs mature species Control and NleVilcKO crypts. Hybridization with probes against the its1 (central panel) or its2 (right panel) shows precursors of the small and large ribosomal subunit, respectively. Black arrows indicate the accumulation of the 32 and $12 \mathrm{~S}$ precursors of the large ribosomal subunit in NleVilcKO crypts. (e) Anti-puromycin immunoblotting of protein extracts for identical number of crypts cells from Control and NleVilcKO intestine at day 2 p.i. Results obtained from two independent experiments are shown. Graphs represent the mean normalized intensity \pm S.E.M. $n=4$ for each genotype. $P>0.05$ Mann-Whitney Wilcoxon test

These data strongly suggest that Muc2 is a direct p53 target gene and provide insights into the contribution of p53 to the goblet cell differentiation phenotype.

Removal of Nle-deficient ISCs persists independently of p53. Presence of the Nle recombined allele was monitored by genomic PCR on NleVilcKO; p53KO crypts at different times after tamoxifen injection (Figure 8a). This analysis revealed that the replacement of Nle-deficient intestinal epithelium by Nle-proficient cells occurred between days 4 and 10 p.i. in a p53-deficient background. Therefore, Nle mutant ISCs were not maintained even in the absence of p53. We next analyzed cell death in NleVilcKO; p53KO intestine. Interestingly, increased apoptosis was observed in NleVilcKO; p53KO crypts at day 2 p.i. (Figures $8 b$ and c), even though the expression of proapoptotic genes was not induced (Supplementary Figure S5). Contrary to NleVilcKO; p53+/ - crypts, Caspase 3-positive cells were found more rarely at the crypt base and more frequently in the upper third of the crypt where progenitors normally exit cell cycle (Figure $8 \mathrm{~d}$ ). In the absence of p53, Nle-deficient intestinal progenitors seem therefore to progress further along the differentiation pathway before possibly being eliminated through p53-independent apoptosis. As Nle deficiency does not affect protein synthesis at day 2 p.i. (Figure 4e), defects in protein translation are unlikely to be the primary cause of p53-independent cell death at that time. At day 4 p.i., a diminution, although nonsignificant, in protein synthesis was observed in NleVilcKO; p53KO crypts compared with Control; p53KO (Figure 8e) suggesting that deregulated protein 
a

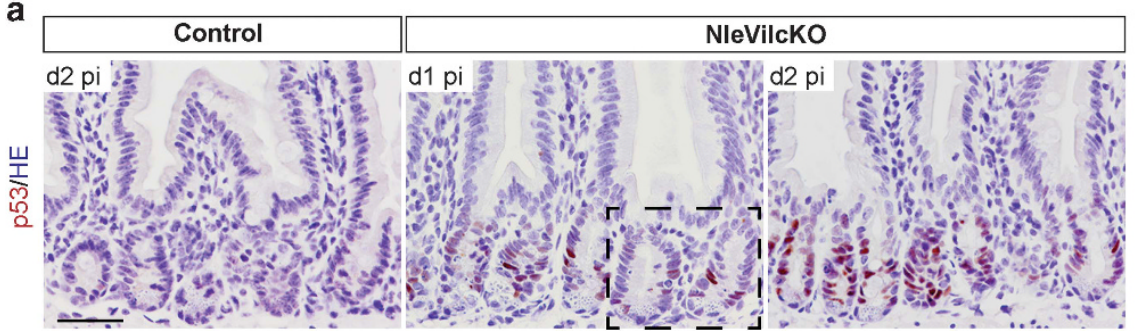

b

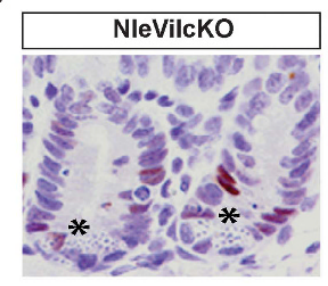

c

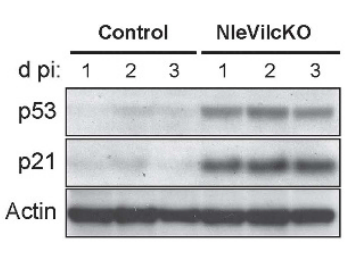

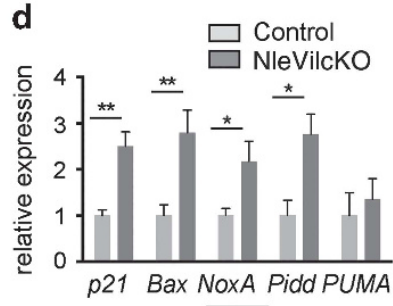

d2 pi

Figure 5 p53 is activated in ISCs and progenitors following Nle deletion. (a and $\mathbf{b})$ p53 immunostaining on intestinal sections from Control and NleVilcKO intestine. Asterisks indicate ISCs with nuclear accumulation of p53. Scale bar, $50 \mu \mathrm{m}$. (b) Magnified view of the framed region in a. (c) Western blot for p53, p21 and $\alpha$-Actin performed on crypts enriched protein extracts from Control and NleVilcKO intestines. (d) RT-qPCR performed on mRNA from Control (gray bars) and NleVilcKO (red bars) intestinal extracts. Graphs represent the mean fold changes \pm S.E.M. of the indicated p53 transcriptionnal targets. $n \geq 5$ for each genotype. ${ }^{*} P<0.05 ;{ }^{* *} P<0.001$ Mann-Whitney Wilcoxon test

synthesis might also contribute to the elimination of Nledeficient ISCs and progenitors in absence of p53.

Altogether these data show that p53-independent mechanisms also participate in the elimination of mutant ISCs and progenitors.

\section{Discussion}

Our data reveal the crucial role of Nle in maintaining adult intestinal homeostasis and stem cells. Higher levels of Nle and nascent rRNA expression are found in crypts compared with villi, and accordingly, ribosome biogenesis dysfunction consecutive to NLE depletion is restricted to the crypt compartment. In response to ribosome biogenesis defects, p53 is activated in ISCs and progenitors, causing their rapid elimination through cell cycle arrest and apoptosis. In addition to these well-described stress responses, we found that p53 also triggers the premature differentiation of progenitors into goblet cells. Although premature differentiation may represent an efficient way to remove damaged or unfit stem/progenitor cells from active pools, few examples have been documented so far. In response to DNA damage in embryonic stem cells, p53 induces differentiation through direct repression and activation of pluripotency- and differentiation-associated genes respectively. ${ }^{32}$ In adult melanocyte and hematopoietic stem cells, premature differentiation in response to genotoxic stress occurs independently of $\mathrm{p} 53 .{ }^{33,34}$ Muc2 expression was upregulated both in NleVilcKO crypts and in CX-5641-treated organoids. Together with the identification of functional p53 response elements within the Muc2 gene, this indicates that p53 has a direct transcriptional control on the differentiation of intestinal cells toward the goblet cell lineage in response to ribosome biogenesis defects. Interestingly, a previous study reported the transcriptional activation of MUC2 by $\mathrm{p53}$ in human colon cancer cell lines, ${ }^{35}$ suggesting that such mechanism could also be operating in humans. Whether p53 transcriptionally regulates the expression of other genes associated with the goblet cell differentiation program would require further studies. It would also be interesting to determine if p53-dependent differentiation responses are elicited in other organs following ribosome biogenesis defects.

Nle acts in large ribosomal subunit in yeasts, ${ }^{20,21}$ fungi, ${ }^{36}$ plants ${ }^{37}$ and mammals. ${ }^{23}$ Contrary to Drosophila, ${ }^{38}$ Nle loss of function does not seem to interfere with the Notch pathway in the mouse hematopoietic ${ }^{23}$ and intestinal (this study) lineages. Indeed, although increasing or decreasing Notch activity systematically results in strong variations of Hes1 expression levels in the intestinal crypt cells, ${ }^{39-43}$ Hes 1 mRNA levels were unchanged following Nle inactivation in the intestinal epithelium (Figure 3c and data not shown). Interestingly, premature differentiation toward the goblet cell lineage of intestinal stem/ progenitor cells is observed when Notch activity is inhibited. $^{39,41-43}$ In view of our results, it would therefore be important to determine whether p53 participates in the hypersecretory phenotype of Notch-defective intestinal epithelium.

This work also unravels the existence of p53-independent responses to ribosomal stress in the intestine including progenitors apoptosis and ISCs disappearance. In human cancer cell lines, p53-independent mechanisms linking ribosome biogenesis defects to cell cycle arrest have been reported. $^{44,45}$ Interestingly, binding of RPL11 to MDM2 was shown to inhibit its E2F1-stabilizing activity, thereby hindering cell cycle progression. ${ }^{44}$ Increased binding of RPL11 to MDM2 consecutive to ribosome biogenesis dysfunction could therefore potentially interfere with other p53-independent functions of MDM2 such as inhibition of apoptosis. ${ }^{46-48}$ So far, such functions has been described in cell lines and it will be interesting in future studies to evaluate their contribution to the phenotype of NleVilcKO; p53KO mice.

Besides the activation of p53-dependent and independent checkpoints, defective ribosome biogenesis is likely to confer Nle-deficient ISCs/progenitors with a cell proliferation 

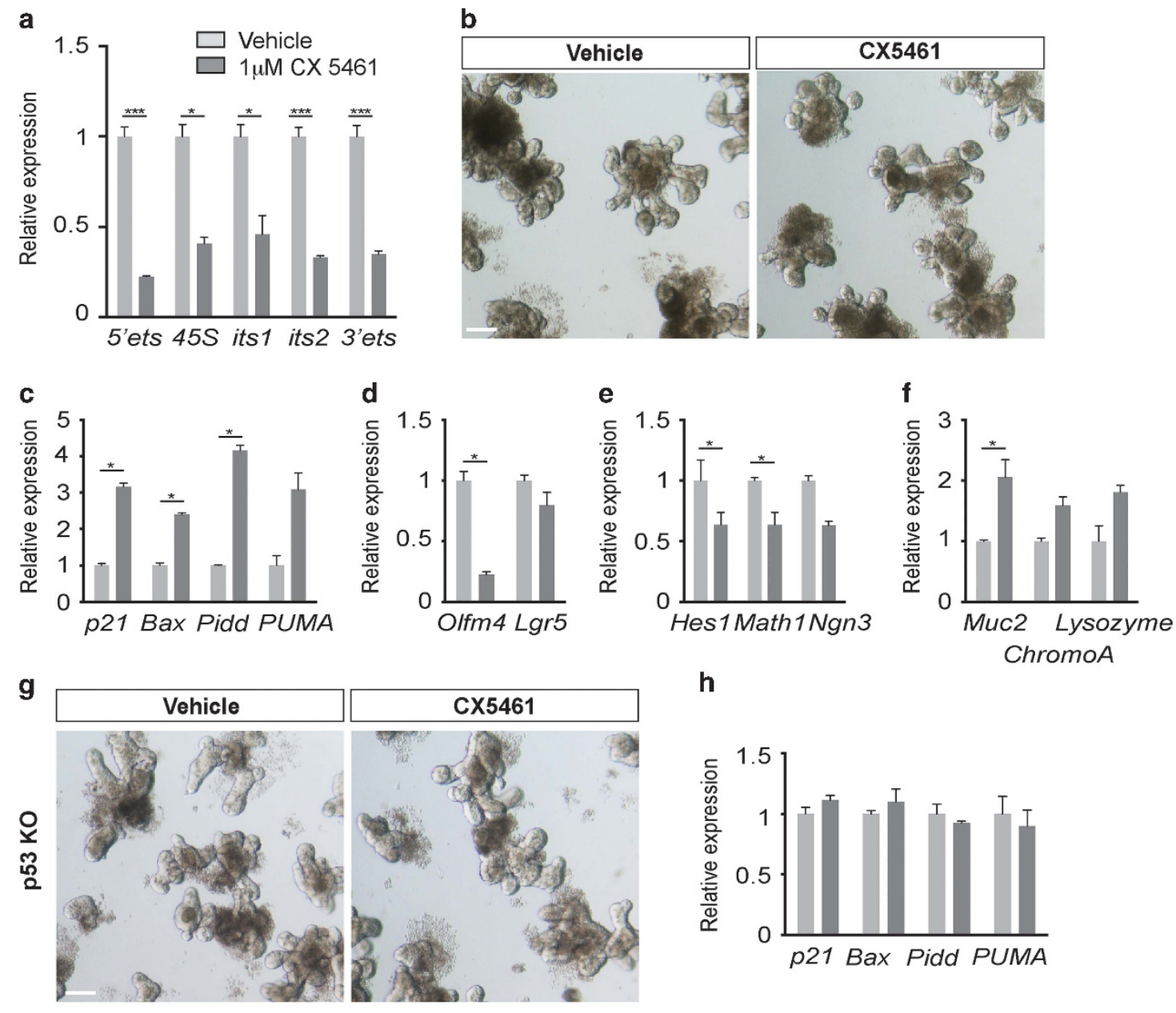

h

ChromoA

i

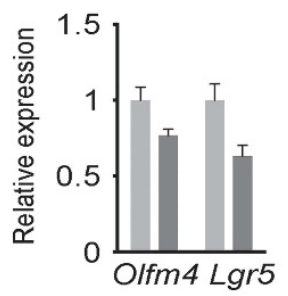

j

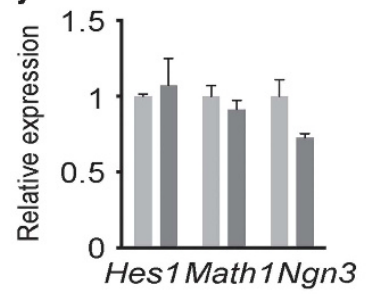

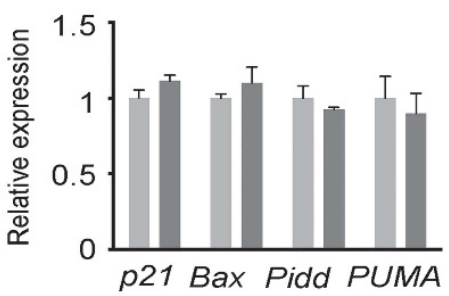

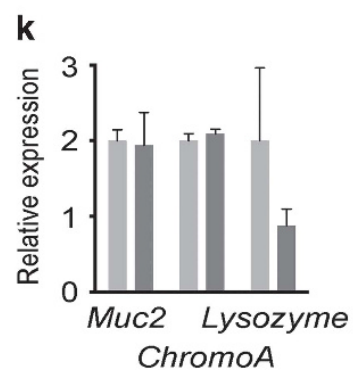

Figure 6 Incubation of intestinal organoids with the rRNA polymerase I inhibitor CX-5461 recapitulates the NleVilcKO phenotypes. (a) RT-qPCR performed on mRNA from vehicle or CX-5461 treated organoids after $1 \mathrm{~h}$ incubation. Graphs represent the mean fold changes \pm S.E.M. for rRNA precursors. $n=3$ for each condition. ${ }^{*} P<0.05$; ${ }^{* * *} P<0.0001$ multiple Student test with the Holm-Sidak correction method. (b and $\left.\mathbf{g}\right)$ Pictures of organoids obtained from WT (b) or P53 KO mice (g), after 1 day incubation with vehicle or CX-5461. Scale bars, $20 \mu \mathrm{m}$. (c-f) and (h-j), RT-qPCR performed on mRNA from vehicle or CX-5461 treated organoids 1 day after addition of vehicle or CX-5461. Expression levels of p53 effectors, and markers of CBCs, progenitors and differentiated intestinal cells are shown. Graphs represent the mean fold changes \pm S.E.M. $n \geq 3$ for each condition. ${ }^{*} P<0.05$ Mann-Whitney Wilcoxon test

disadvantage due to decreased ribosome content and reduced rate of translation. Indeed, the reduced levels of RPL5 or RPL11 in human lung fibroblasts was recently shown to reduce their translational capacity and impede their proliferation. ${ }^{49} \mathrm{~A}$ similar mechanism was proposed to account for the delayed larval development and reduced body size of Drosophila minute mutants harboring hypomorphic mutations in ribosomal proteins. ${ }^{50}$ When surrounded by wild-type cells, minute clones are outcompeted and disappear (for review, see Amoyel and Bach $^{51}$ ). Thus, such cell competition phenomena might also contribute to the replacement of Nle-deficient crypt cells by cells that have escaped recombination. Another possibility is that reduced ribosome biogenesis would alter the self-renewal of Nle-deficient ISCs. Support from this hypothesis comes from the recent demonstration that modulation of ribosome DNA transcription and ribosome biogenesis is directly influencing the self-renewal properties of Drosophila germ stem cells. ${ }^{52}$

Ribosome production is increased in cancer cells and deregulation of ribosome biogenesis is associated with increased risks of developing cancer. ${ }^{53,54}$ In human colorectal 

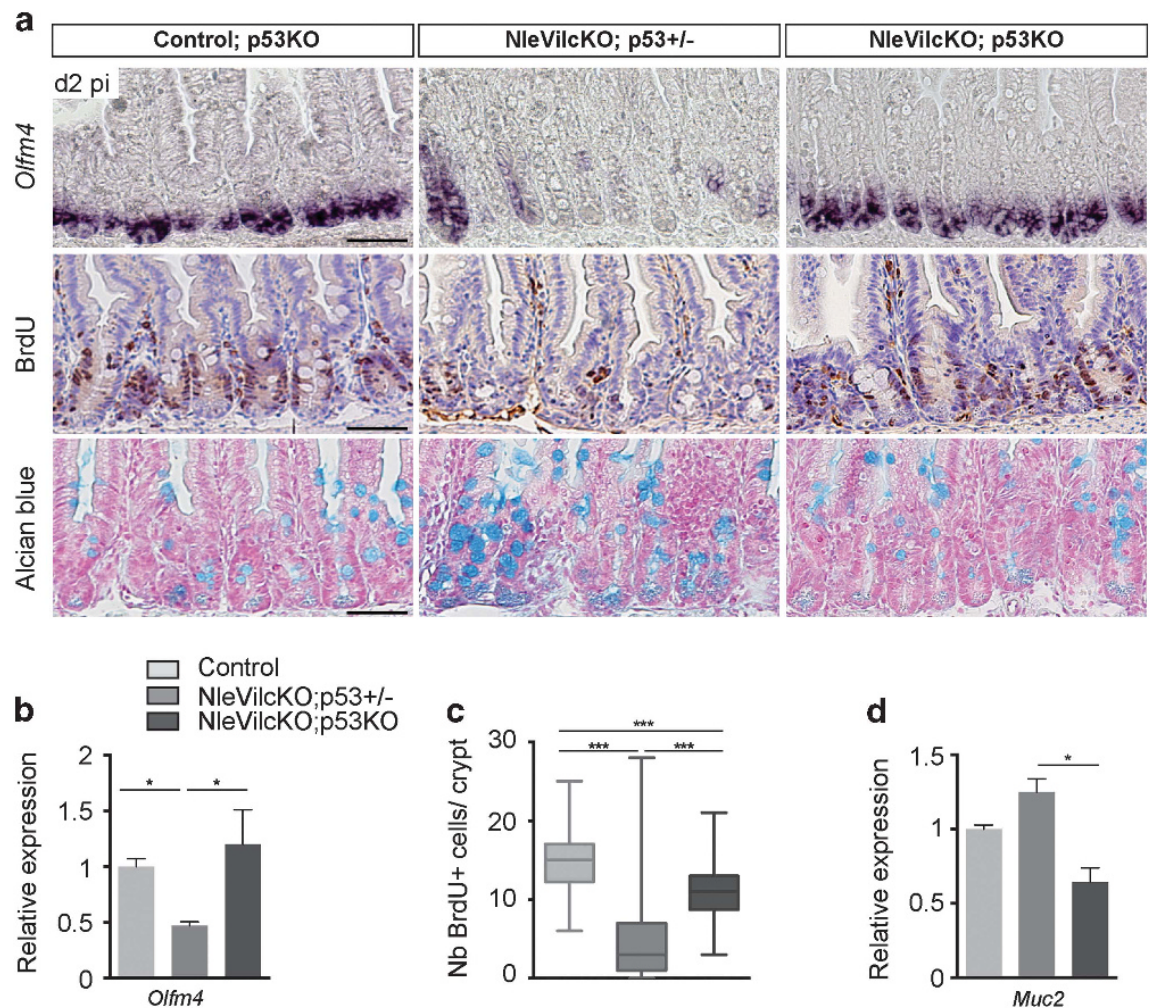

e

Muc2-001

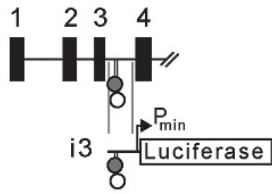

i3 $\Delta \rightarrow \rightarrow_{\text {Luciferase }}^{P_{\text {min }}}$

$\mathbf{f}$

$$
\begin{array}{llc}
\text { RRRCWWGYYY (0-13) } & \text { RRRCWWGYYY } & 16.49 \\
\text { AGCCTTGCCT (ggtggagca) } & \text { AGGCATGTT } & \\
1709 & \text { RRRCWWGYYY (0-13) RRRCWWGYYY } & 11.68 \\
& \text { AGGCATGTTT (cag) AGCCAAGgaC } & \\
& & 1749
\end{array}
$$

9

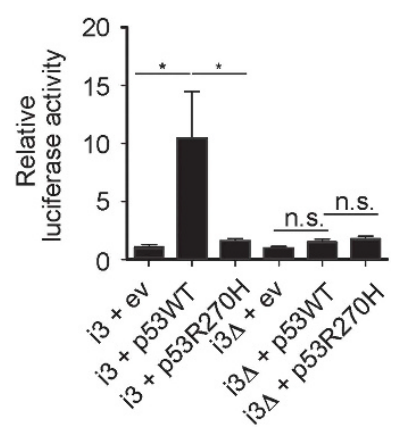

Figure 7 Cell cycle exit and differentiation of intestinal SCs and progenitors toward the goblet cell lineage depend on p53. (a) Olfm4 in situ hybridization, BrdU immunostaining and alcian blue staining on sections of Control; p53KO, NleVilcKO; p53+/ - and NleVilcKO; p53KO intestines. (b and c) Histogram showing Olfm4 mRNA levels and mean number \pm S.E.M. of BrdU-positive cells per crypt in Control; p53KO, NleVilcKO; p53+l - and NleVilcKO; p53KO small intestine. $n=4$ for each genotype. (d) RT-qPCR performed on mRNA from Control, NleVilcKO; p53+/ - and NleVilcKO; p53KO intestines at day 2 p.i. showing the level of Muc2 expression. Graphs represent the mean fold changes \pm S.E. M. $n \geq 3$ for each genotype. (e) Partial map of the Muc2 gene corresponding to the $5^{\prime}$ region of the Muc2-001 Ensembl transcript and showing the putative p53 REs (Iollipops) within intron 3. The maps of Luciferase reporter plasmids are shown, with plasmid i3 containing WT sequences from Muc2 intron 3 , plasmid i3 $\Delta$ containing the intron 3 deleted for both p53 REs. (f) DNA sequences of the partially overlapping p53 REs identified within Muc2 intron 3. On top, the consensus sequence for a p53 RE is shown, with two p53binding half-sites separated by 0-13 nucleotides. The p53 REs are shown, with putative half-sites having 0-3 mismatches with the consensus (matches in capital letters and mismatches in lowercase). Numbers are relative to the transcription start site. (g) Luciferase reporter assay. The i3 or i $3 \Delta$ plasmid were transfected in $\mathrm{p}^{2} 3^{-/-} \mathrm{MEF}$ together with an empty vector (ev), an expression vector encoding WT p53 (p53WT) or mutant p53 (p53R270H). The graph shows luciferase activity normalized to the control renilla luciferase. Three independent experiments were plotted. ${ }^{*} P<0.05$ Student's $t$-test

cancer, increase in the levels of many ribosomal proteins was reported and the expression patterns of specific RPs were associated with tumor differentiation, progression or metastasis status. ${ }^{55}$ Furthermore, a germline mutation in the Rps20 gene was recently shown to cause hereditary nonpolyposis colorectal carcinoma predisposition. ${ }^{53}$ Finally, in patients with ulcerative colitis, IL-6-mediated stimulation of ribosome biogenesis and subsequent decrease in p53 levels were recently proposed as a possible mechanism favoring cancer progression in colonic mucosa exposed to chronic inflammation. ${ }^{56}$ Future investigations using the NleVilcKO model will help to obtain a deeper understanding on the mechanisms that link ribosomes biogenesis to intestinal cancer.

\section{Materials and methods}

Mice. Experiments on mice were conducted according to the French and European regulations on care and protection of laboratory animals (EC Directive 86/609, French Law 2001-486 issued on 6 June 2001) and the National Institutes of 


\begin{tabular}{|c|c|c|c|c|c|c|c|c|}
\hline \multirow[b]{2}{*}{$\mathrm{T}$} & \multicolumn{4}{|c|}{ Control;p53KO } & \multicolumn{4}{|c|}{ NleVilcKO;p53KO } \\
\hline & d2 & $\mathrm{d} 4$ & d10 & d60 & d2 & d4 & d10 & d60 \\
\hline 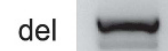 & $=$ & 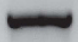 & $=$ & $=$ & $=$ & $=$ & & $x^{2}$ \\
\hline$\longrightarrow$ & $\longrightarrow$ & $\longrightarrow$ & $\longrightarrow$ & $\longrightarrow$ & $\longrightarrow$ & $\longrightarrow$ & $=$ & $=$ \\
\hline
\end{tabular}

\section{b}

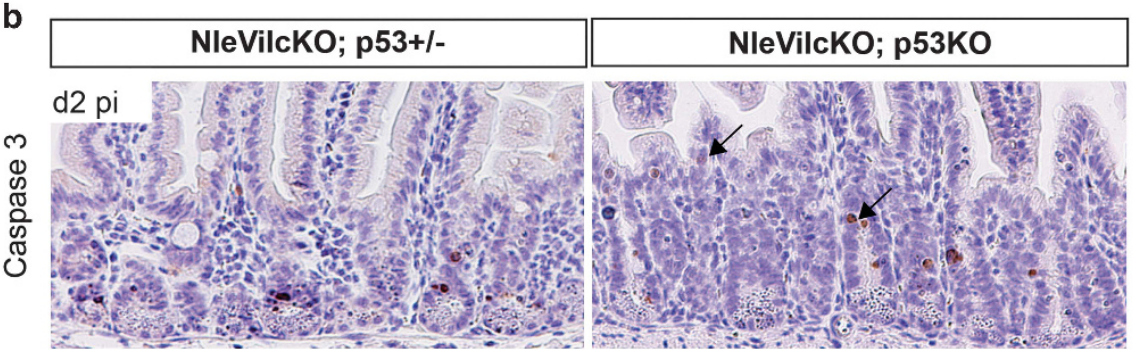

C

NleVilcKO;p53+/-

NleVilcKO;p53KO

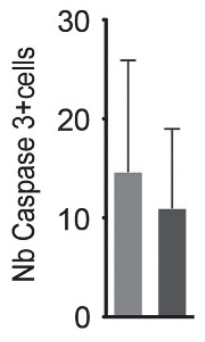

d

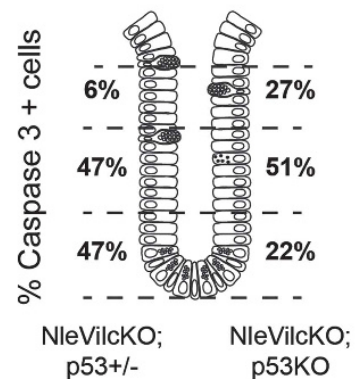

e

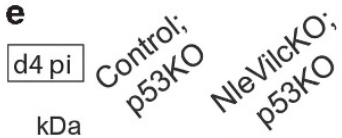

$\mathrm{kDa}$

170

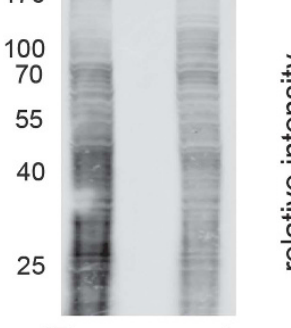

IB: puromycin $\square$ Control;p53KO NleVilcKO;p53KO

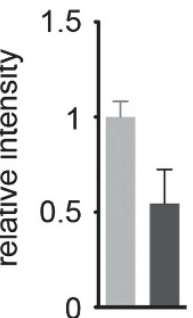

Figure 8 p53-independent elimination of Nle mutant intestinal SCs and progenitors. (a) Detection of the nonrecombined (flox) and recombined (del) Nle alleles by genomic PCR performed on crypts (c) or villi (v) enriched DNA extracts from Control; p53KO and NleVilcKO; p53KO intestines. (b) Caspase 3 immunostaining on sections of NleVilcKO; p53+/ - and NleVilcKO; p53KO intestines. Arrows show apoptotic cells located in the upper crypt region. Scale bars, $50 \mu \mathrm{m}$. (c) Histogram showing the mean number ( \pm S.E.M.) of Caspase 3-positive cells per crypt in NleVilcKO; p53+/ - and NleVilcKO; p53KO small intestine. $n=3$ for each genotype. (d) Diagram representing the percentage of Caspase 3-positive cells found in the lower, middle and upper thirds of the crypts in NleVilcKO; p53+/ - and NleVilcKO; p53KO small intestine. (e) Anti-puromycin immunoblotting of protein extracts for identical number of crypts cells from Control; p53KO and NleVilcKO; p53KO intestine at day 4 p.i. Graphs represent the mean normalized intensity \pm S.E.M. $n=3$ for each genotype

Health Animal Welfare (Insurance \#A5476-01 issued on 02/07/2007). The alleles used were as follows: $\mathrm{Nle}^{\text {flox } 23} \mathrm{NIl}^{\text {null }} 24$ Villin-CreERT2, ${ }^{57}$ Lgr5 ${ }^{\text {GFP-IRES-CreERT2 } 58}$ p53 ${ }^{59}$ To generate Control and NleVilcKO mice, Villin-CreERT2 ${ }^{\text {tg/tg; }} \mathrm{Nie}^{\text {flox fllox }}$ mice were crossed to $\mathrm{Nle}^{\text {null/++}}$ mice. Mice at 5 to 6 weeks of age were injected intraperitoneally with $75 \mathrm{mg} / \mathrm{kg}$ tamoxifen for three consecutive days. For proliferation assays, mice were injected with BrdU $(100 \mathrm{mg} / \mathrm{kg}) 2.5 \mathrm{~h}$ before killing.

Tissue extracts. For paraffin sections, the intestinal tract was dissected, flushed twice with ice-cold PBS to remove any fecal content and perfused with icecold $4 \%$ paraformaldehyde (PFA). The small intestine was rolled up from the proximal to the distal end in concentric circles, fixed in $4 \%$ PFA at $4{ }^{\circ} \mathrm{C}$ overnight, dehydrated, and embedded in paraffin wax. For RT-qPCR on total intestine, $1 \mathrm{~cm}$ of duodenum was harvested in $1 \mathrm{ml}$ Trizol (Invitrogen, Carlsbad, CA, USA). For crypts and villi isolation, $5-10 \mathrm{~cm}$ of jejunum were collected, opened longitudinally and processed as previously described. ${ }^{60}$

Histology and immunostaining. Histology and immunostaining were performed as described previously. ${ }^{61}$ Specific antibodies binding was detected using either biotinylated secondary antibodies and Streptavidin/HRP complexes (Dako, Glostrup, Denmark), or ImmPRESS-HRP (Vector Laboratories, Burlingame, CA, USA). Bright field microscopy was performed using a Zeiss Axiophot microscope, or a MiraxScan device (Carl Zeiss microlmaging, Goettingen, Germany) equipped with a $20 \times$ objective lens. The system was set to run in automated batch mode with automated focus and tissue finding. For immunofluorescence staining, sections were mounted in vectashield and images were acquired with an upright microscope Zeiss Axiovert $200 \mathrm{M}$ with a Zeiss apotome system controlled by the Zeiss axiovision 4.4 software. Primary and secondary antibodies used in this study are listed in Supplementary material Supplementary Table S2.

In situ hybridization. Digoxigenin-labeled Olfm4 antisense probe was synthesized from a plasmid containing Olfm4 cDNA (Gift from B Romagnolo, Cochin Institute, Paris) using T7 RNA polymerase and Dig labeling kit (Roche Diagnostics, Basel, Switzerland). Paraffin sections $(8 \mu \mathrm{m})$ were rehydrated and treated with $15 \mu \mathrm{g} / \mathrm{ml}$ Proteinase $\mathrm{K}$ for $15 \mathrm{~min}$. Proteinase $\mathrm{K}$ was inactivated with a 1 min wash in $0.2 \%$ Glycin in PBS-Tween. Sections were postixed in 4\% PFA for $10 \mathrm{~min}$ and washed several times in PBS- $0.1 \%$ tween. Prehybridization was carried out for $1 \mathrm{~h}$ at $65^{\circ} \mathrm{C}$ in $50 \%$ deionized formamide, $2 \times$ sodium saline citrate (SSC), $50 \mu \mathrm{g} / \mathrm{ml}$ yeast tRNA and $50 \mu \mathrm{g} / \mathrm{ml}$ Heparin. Hybridization was performed overnight at $65^{\circ} \mathrm{C}$ with the riboprobe diluted in prehybridization mix, and was followed by washes in $50 \%$ formamide/ $2 \times \mathrm{SSC}$ at $65^{\circ} \mathrm{C}$ for $1 \mathrm{~h}$. Sections were washed for an additional hour in maleate buffer ( $100 \mathrm{mM}$ maleic acid, $150 \mathrm{mM} \mathrm{NaCl}, 0,1 \%$ tween) at room temperature, and incubated for $1.5 \mathrm{~h}$ with the anti-digoxigenin alkaline phosphatase-conjugated antibody (dilution, 1:500, in Blocking Buffer, Roche Diagnostics). Sections were then washed in maleate buffer before incubation with the chromogenic substrates of alkaline phosphatase, 5-bromo-4-chloro-3-indolyl- 
phosphate $(0.175 \mathrm{mg} / \mathrm{ml})$ and NBT $(0.337 \mathrm{mg} / \mathrm{ml})$ (Roche Diagnostics), in $100 \mathrm{mM}$ Tris (pH 9.5), $100 \mathrm{mM} \mathrm{NaCl}$, and $50 \mathrm{mM} \mathrm{MgCl} 2$ at room temperature.

For fluorescent in situ hybridization, the hybridization step was performed as previously described ${ }^{62}$ Conjugated FISH probes were purchased from Eurogentec: its1-Cy5: tagacacggaagagccggacgggaaaga; its2-Cy3: gcgattgatcgtcaaccgacgctc; 28S-Alexa488: cccgttcccttggctgtggtttcgctggata; 18S-Cy5: ttacttcctctagatagtcaagttc gacc and validated in a previous study. ${ }^{23}$

Crypts culture. Isolated crypts were cultured as previously described. ${ }^{26}$ In brief, 450 crypts were embedded in growth factor reduced matrigel (Corning LifeSciences, Tewksbury, MA, USA) and plated in 24-wells plates with culture medium (Advanced DMEM/F12; Invitrogen) containing EGF (Peprotech, Rocky Hill, NJ, USA); R-spondin 1 (R\&D Systems, Minneapolis, MN, USA); and noggin (Peprotech); and supplemented with N2 and B27 (Invitrogen). The medium was exchanged every 4 days. For CX-5461 treatment, organoids were cultured for

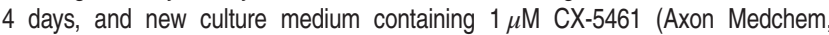
Groningen, The Netherlands) diluted in $0,1 \mathrm{M}$ citrate. $0,1 \mathrm{M}$ citrate only was added as a vehicle control.

RT-qPCR. For total RNAs extraction, intestinal samples were homogenized in Trizol containing $0.4 \mathrm{~g}$ of glass beads $(212-300 \mu \mathrm{m} ø$, Sigma, St. Louis, MO, USA for $40 \mathrm{~s}$ in a FastPrep Instrument (MP Biochemicals, Illkirch, France). To extract their RNAs, organoids were recovered from Matrigel and processed following the mRNeasy mini kit procedure (Qiagen Sciences, Germantown, MD, USA). Reversetranscription was performed using the Superscript II kit (Invitrogen) according to the manufacturers' instructions. Real-time PCR was carried on using custom-designed primers (Supplementary Table S1) and SYBR green PCR master mix (Applied Biosystem, Foster city, CA, USA) on a StepOne instrument (StepOne software version 2.2; Applied Biosystems). Expression levels were normalized using TBP, Aldolase and/or Rrm2 as reference genes.

Western blot. Proteins were extracted in a urea buffer supplemented with antiproteases (Roche Diagnostics) and $1 \mathrm{mM}$ DTT. Extracts were sonicated $5 \mathrm{~min}$ and treated with Benzonase (Sigma) to get rid of DNA contaminants. The protein content was determined using a Bradford assay. Proteins were denatured in Laemmli buffer at $95^{\circ} \mathrm{C}$ for $10 \mathrm{~min}$ before being loaded on a $10 \%$ polyacrylamide gel. After migration, proteins were transferred onto a nitrocellulose membrane (Biorad, Hercules, CA, USA) and incubated overnight at $4{ }^{\circ} \mathrm{C}$ with the primary antibodies. Membranes were incubated with peroxidase labeled secondary antibodies at RT for $45 \mathrm{~min}$, rinsed in PBS. Signals were visualized using $\mathrm{ECl}$ (Pierce Biotechnology, Rockford, IL, USA) and quantified on a Typhoon Instrument. Primary and secondary antibodies used in these experiments are listed in supplementary material Supplementary Table S2.

Quantification of protein synthesis. Mice were injected intraperitoneally with $1 \mathrm{mg}$ of puromycin in PBS, $10 \mathrm{~min}$ before killing. Intestines were rapidly harvested in ice-cold PBS containing emetine to block puromycin incorporation during the procedure. Crypts were isolated as described previously, and dissociated into single cells. Single cells were counted on a hemocytometer before being lysed in protein extraction buffer. Puromycilated peptide chains were quantified on a western blot against puromycin by measuring the pixel intensity through the whole length of each lane using typhoon instrument.

Northern blot. Total RNA from crypts cells was prepared with TRIzol reagent following the supplier's instructions (Sigma). Migration and hybridization were performed as previously described. ${ }^{63}$ The probes used in this study were Its1-1a (5'-ACGCCGCCGCTCCTCCACAGTCTCCCGTT-3) and Its2-2 (5'-ACTGGTGAGG CAGCGGTCCGGGAGGCGCCGACG-3).

In silico search for putative p53 response elements. To identify putative p53 REs, we used the Consite software (http://consite.genereg.net/) with a positional frequency matrix for $\mathrm{p} 53$ response elements modified to take varying spacer lengths (0-13 bp) into account. With this method, p53 REs from known p53 target genes were previously found to have a mean value (M) of 11.7, with a S.D. of 1.2. Putative REs were plotted against the map as lollipops, with greytones according to their score: white for scores between 10.5 and $12.9(\mathrm{M} \pm$ S.D.) and black for scores $>15.3$ (M+3S.D.).
Luciferase expression assays. To construct the p53 RE reporter plasmids, we cloned intronic sequences upstream of a SV40 minimal promoter before the firefly luciferase gene. For each experiment, $10^{6}$ exponentially growing $\mathrm{p}^{2} 3^{-/-}$ mouse embryonic fibroblasts were nucleofected using the Lonza MEF2 nucleofector kit with $3 \mu \mathrm{g}$ of a p53 RE-firefly luciferase reporter plasmid (i3 or i3 $\Delta$ ) and $3 \mu \mathrm{g}$ of an empty expression plasmid, $3 \mu \mathrm{g}$ of the same reporter plasmid and $3 \mu \mathrm{g}$ of a WT p53 expression plasmid or $3 \mu \mathrm{g}$ of the same reporter plasmid and $3 \mu \mathrm{g}$ of a $\mathrm{p} 53^{\mathrm{R} 270 \mathrm{H}}$ expression plasmid. For all points, data were normalized by adding $30 \mathrm{ng}$ of renilla luciferase expression plasmid (pGL4.73, Promega, San Luis Obispo, CA, USA). Nucleofected cells were allowed to grow for $24 \mathrm{~h}$, then trypsinized, resuspended in $75 \mu \mathrm{l}$ culture medium and transferred into a well of an optical 96 well plate (Nunc, ThermoFisherScientific, Rugby, UK). The dual-glo luciferase assay system (Promega) was used according to the manufacturer's protocol to lyse the cells and read firefly and renilla luciferase signals.

Statistical analysis. Graphs were performed using Prism5 software (GraphPad Software, La Jolla, CA, USA). For mean comparisons, all bar graphs with pooled data show means \pm S.E.M. Statistical analyses were performed using the Mann-Whitney Wilcoxon test or the Student's $t$-test. $P<0.05$ was considered significant.

\section{Conflict of Interest}

The authors declare no conflict of interest.

Acknowledgements. We are grateful to the members of the histopathology unit and of B Romagnolo's team and to A David and S El Messaoudi-Aubert for technical

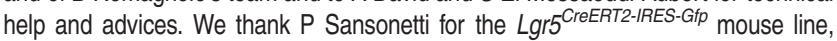
B Romagnolo for the Olfm4 in situ probe and B Gayraud-Morel, L Le Cam, JC Marine for providing reagents. We thank B Romagnolo, $\mathrm{P}$ Jay and $\mathrm{J}$ Artus for critical reading of the manuscript, and all members of the Glstem consortium, S Tajbakhsh's lab and the Mouse Functional Genetics unit for helpful discussions. Imaging was performed at the Imagopole and the histopathology Unit from Institut Pasteur. This work was supported by the Institut National du Cancer (INCa 2007-1-COL-6-IC-1 and PLBIO09-070), the Institut Pasteur, the Centre National de la Recherche Scientifique, the Agence Nationale de la Recherche (ANR-10-LABX-73-01 REVIVE) and the Fondation ARC (Programme labellisé 2014). AS received support from the Fondation des Treilles.

1. Fromont-Racine M, Senger B, Saveanu C, Fasiolo F. Ribosome assembly in eukaryotes. Gene 2003; 313: 17-42.

2. Wild T, Horvath $\mathrm{P}$, Wyler E, Widmann B, Badertscher L, Zemp I et al. A protein inventory of human ribosome biogenesis reveals an essential function of exportin 5 in $60 \mathrm{~S}$ subunit export. PLOS Biol 2010; 8: e1000522.

3. Sloan KE, Mattijssen S, Lebaron S, Tollervey D, Pruijn GJM, Watkins NJ. Both endonucleolytic and exonucleolytic cleavage mediate ITS1 removal during human ribosomal RNA processing. J Cell Biol 2013; 200: 577-588.

4. Carron C, O'Donohue M-F, Choesmel V, Faubladier M, Gleizes P-E. Analysis of two human pre-ribosomal factors, bystin and hTsr1, highlights differences in evolution of ribosome biogenesis between yeast and mammals. Nucleic Acids Res 2011; 39: 280-291.

5. Tafforeau L, Zorbas C, Langhendries J-L, Mullineux S-T, Stamatopoulou V, Mullier R et al. The complexity of human ribosome biogenesis revealed by systematic nucleolar screening of Pre-rRNA processing factors. Mol Cell 2013; 51: 539-551.

6. Donati G, Peddigari S, Mercer CA, Thomas G. 5 S ribosomal RNA is an essential component of a nascent ribosomal precursor complex that regulates the Hdm2-p53 checkpoint. Cell Rep 2013; 4: 87-98.

7. Zhang Y, Wolf GW, Bhat K, Jin A, Allio T, Burkhart WA et al. Ribosomal protein L11 negatively regulates oncoprotein MDM2 and mediates a p53-dependent ribosomal-stress checkpoint pathway. Mol Cell Biol 2003; 23: 8902-8912.

8. Fumagalli S, Ivanenkov VV, Teng T, Thomas $G$. Suprainduction of $p 53$ by disruption of $40 \mathrm{~S}$ and $60 S$ ribosome biogenesis leads to the activation of a novel G2/M checkpoint. Genes Dev 2012; 26: 1028-1040.

9. Armistead J, Triggs-Raine B. Diverse diseases from a ubiquitous process: the ribosomopathy paradox. FEBS Lett 2014; 588: 1491-1500.

10. Narla A, Ebert BL. Ribosomopathies: human disorders of ribosome dysfunction. Blood 2010; 115: 3196-3205.

11. McGowan KA, Li JZ, Park CY, Beaudry V, Tabor HK, Sabnis AJ et al. Ribosomal mutations cause p53-mediated dark skin and pleiotropic effects. Nat Genet 2008; 40: 963-970.

12. Dutt S, Narla A, Lin K, Mullally A, Abayasekara N, Megerdichian C et al. Haploinsufficiency for ribosomal protein genes causes selective activation of p53 in human erythroid progenitor cells. Blood 2011; 117: 2567-2576. 
13. Stadanlick JE, Zhang Z, Lee S-Y, Hemann M, Biery M, Carleton MO et al. Developmental arrest of $T$ cells in Rpl22-deficient mice is dependent upon multiple p53 effectors. $J$ Immunol 2011; 187: 664-675.

14. McGowan KA, Pang WW, Bhardwaj R, Perez MG, Pluvinage JV, Glader BE et al. Reduced ribosomal protein gene dosage and p53 activation in low-risk myelodysplastic syndrome. Blood 2011; 118: 3622-3633

15. Pereboom TC, van Weele LJ, Bondt A, Maclnnes AW. A zebrafish model of dyskeratosis congenita reveals hematopoietic stem cell formation failure resulting from ribosomal proteinmediated p53 stabilization. Blood 2011; 118: 5458-5465.

16. Jaako P, Flygare J, Olsson K, Quere R, Ehinger M, Henson A et al. Mice with ribosomal protein $\mathrm{S} 19$ deficiency develop bone marrow failure and symptoms like patients with Diamond-Blackfan anemia. Blood 2011; 118: 6087-6096.

17. Torihara H, Uechi T, Chakraborty A, Shinya M, Sakai N, Kenmochi N. Erythropoiesis failure due to RPS19 deficiency is independent of an activated Tp53 response in a zebrafish model of Diamond-Blackfan anaemia. Br J Haematol 2011; 152: 648-654.

18. Provost E, Wehner KA, Zhong X, Ashar F, Nguyen E, Green R et al. Ribosomal biogenesis genes play an essential and p53-independent role in zebrafish pancreas development. Development 2012; 139: 3232-3241.

19. Yadav GV, Chakraborty A, Uechi T, Kenmochi N. Ribosomal protein deficiency causes Tp53-independent erythropoiesis failure in zebrafish. Int J Biochem Cell Biol 2014; 49: 1-7.

20. la Cruz de J, Sanz-Martínez E, Remacha M. The essential WD-repeat protein Rsa4p is required for $r R N A$ processing and intra-nuclear transport of $60 \mathrm{~S}$ ribosomal subunits. Nucleic Acids Res 2005; 33: 5728-5739.

21. Ulbrich C, Diepholz M, Baszligler J, Kressler D, Pertschy B, Galani K et al. Mechanochemical Removal of Ribosome Biogenesis Factors from Nascent 60S Ribosomal Subunits. Cell 2009; 138: 911-922.

22. Matsuo Y, Granneman S, Thoms M, Manikas R-G, Tollervey D, Hurt E. Coupled GTPase and remodelling ATPase activities form a checkpoint for ribosome export. Nature 2014; 505: 112-116.

23. Le Bouteiller M, Souilhol C, Cormier S, Stedman A, Burlen-Defranoux O, VandormaelPournin $\mathrm{S}$ et al. Notchless-dependent ribosome synthesis is required for the maintenance of adult hematopoietic stem cells. J Exp Med 2013; 210: 2351-2369.

24. Cormier S, Le Bras S, Souilhol C, Vandormael-Pournin S, Durand B, Babinet C et al. The murine ortholog of notchless, a direct regulator of the notch pathway in Drosophila melanogaster, is essential for survival of inner cell mass cells. Mol Cell Biol 2006; 26: 3541-3549.

25. van der Flier LG, van Gijn ME, Hatzis $P$, Kujala $P$, Haegebarth $A$, Stange DE et al. Transcription factor achaete scute-like 2 controls intestinal stem cell fate. Cell 2009; 136 903-912.

26. Sato T, Vries RG, Snippert HJ, van de Wetering M, Barker N, Stange DE et al. Single Lgr5 stem cells build crypt-villus structures in vitro without a mesenchymal niche. Nature 2009; 459: 262-265.

27. Yang $Q$, Bermingham NA, Finegold MJ, Zoghbi HY. Requirement of Math1 for secretory cell lineage commitment in the mouse intestine. Science 2001; 294: 2155-2158.

28. Noah TK, Donahue B, Shroyer NF. Intestinal development and differentiation. Exp Cell Res 2011; 317: 2702-2710.

29. David A, Dolan BP, Hickman HD, Knowlton JJ, Clavarino G, Pierre P et al. Nuclear translation visualized by ribosome-bound nascent chain puromycylation. J Cell Biol 2012; 197: 45-57.

30. Drygin D, Lin A, Bliesath J, Ho CB, O'Brien SE, Proffitt C et al. Targeting RNA polymerase I with an oral small molecule CX-5461 inhibits ribosomal RNA synthesis and solid tumor growth. Cancer Res 2011; 71: 1418-1430.

31. Simeonova I, Lejour V, Bardot B, Bouarich-Bourimi R, Morin A, Fang M et al. Fuzzy tandem repeats containing p53 response elements may define species-specific p53 target genes. PLOS Genet 2012; 8: e1002731.

32. Li M, He Y, Dubois W, Wu X, Shi J, Huang J. Distinct regulatory mechanisms and functions for p53-activated and p53-repressed DNA damage response genes in embryonic stem cells. Mol Cell 2012; 46: 30-42.

33. Inomata K, Aoto T, Binh NT, Okamoto N, Tanimura S, Wakayama T et al. Genotoxic stress abrogates renewal of melanocyte stem cells by triggering their differentiation. Cell 2009; 137: 1088-1099.

34. Wang J, Sun $Q$, Morita $Y$, Jiang $H, G r o ß ~ A$, Lechel A et al. A differentiation checkpoint limits hematopoietic stem cell self-renewal in response to DNA damage. Cell 2012; 148: 1001-1014.

35. Ookawa K, Kudo T, Aizawa S, Saito H, Tsuchida S. Transcriptional activation of the MUC2 gene by p53. J Biol Chem 2002; 277: 48270-48275.

36. Baßler J, Paternoga H, Holdermann I, Thoms M, Granneman S, Barrio-Garcia C et al. A network of assembly factors is involved in remodeling rRNA elements during preribosome maturation. J Cell Biol 2014; 207: 481-498.

37. Chantha S-C, Matton DP. Underexpression of the plant NOTCHLESS gene, encoding a WD-repeat protein, causes pleitropic phenotype during plant development. Planta 2007; 225: $1107-1120$.
38. Royet J, Bouwmeester T, Cohen SM. Notchless encodes a novel WD40-repeat-containing protein that modulates Notch signaling activity. EMBO J 1998; 17: 7351-7360.

39. van Es JH, van Gijn ME, Riccio O, van den Born M, Vooijs M, Begthel H et al. Notch/gammasecretase inhibition turns proliferative cells in intestinal crypts and adenomas into goblet cells. Nature 2005; 435: 959-963.

40. Fre S, Huyghe M, Mourikis $P$, Robine S, Louvard D, Artavanis-Tsakonas S. Notch signals control the fate of immature progenitor cells in the intestine. Nature 2005; 435: 964-968.

41. Riccio O, van Gijn ME, Bezdek AC, Pellegrinet L, van Es JH, Zimber-Strobl U et al. Loss of intestinal crypt progenitor cells owing to inactivation of both Notch1 and Notch2 is accompanied by derepression of CDK inhibitors p27Kip1 and p57Kip2. EMBO Rep 2008; 9: 377-383.

42. Guilmeau S, Flandez M, Bancroft L, Sellers RS, Tear B, Stanley P et al. Intestinal deletion of Pofut 1 in the mouse inactivates notch signaling and causes enterocolitis. Gastroenterology 2008; 135: 849-860 : 860.e1-6.

43. Pellegrinet L, Rodilla V, Liu Z, Chen S, Koch U, Espinosa L et al. Dll1- and dll4-mediated notch signaling are required for homeostasis of intestinal stem cells. Gastroenterology 2011; 140: 1230-1240.e1-7.

44. Donati G, Brighenti E, Vici M, Mazzini G, Treré D, Montanaro L et al. Selective inhibition of rRNA transcription downregulates E2F-1: a new p53-independent mechanism linking cell growth to cell proliferation. J Cell Sci. 2011; 124: 3017-3028.

45. ladevaia V, Caldarola S, Biondini L, Gismondi A, Karlsson S, Dianzani I et al. PIM1 kinase is destabilized by ribosomal stress causing inhibition of cell cycle progression. Oncogene 2010; 29: $5490-5499$.

46. Kurokawa M, Kim J, Geradts J, Matsuura K, Liu L, Ran X et al. A network of substrates of the E3 ubiquitin ligases MDM2 and HUWE1 control apoptosis independently of p53. Sci Signal 2013; 6: ra32.

47. Gu L, Zhu N, Zhang H, Durden DL, Feng Y, Zhou M. Regulation of XIAP translation and induction by MDM2 following irradiation. Cancer Cell 2009; 15: 363-375.

48. Yang J-Y, Zong CS, Xia W, Yamaguchi $\mathrm{H}$, Ding $Q$, Xie $X$ et al. ERK promotes tumorigenesis by inhibiting FOXO3a via MDM2-mediated degradation. Nat Cell Biol 2008; 10: 138-148.

49. Teng T, Mercer CA, Hexley P, Thomas G, Fumagalli S. Loss of tumor suppressor RPL5/ RPL11 does not induce cell cycle arrest but impedes proliferation due to reduced ribosome content and translation capacity. Mol Cell Biol 2013; 33: 4660-4671.

50. Morata G, Ripoll P. Minutes: mutants of drosophila autonomously affecting cell division rate. Dev Biol 1975; 42: 211-221.

51. Amoyel M, Bach EA. Cell competition: how to eliminate your neighbours. Development2014; 141: $988-1000$

52. Zhang $Q$, Shalaby NA, Buszczak M. Changes in rRNA transcription influence proliferation and cell fate within a stem cell lineage. Science 2014; 343: 298-301.

53. Lai M-D, Xu J. Ribosomal proteins and colorectal cancer. Curr Genomics 2007; 8: 43-49.

54. Stumpf CR, Ruggero D. The cancerous translation apparatus. Curr Opin Genet Dev 2011; 21: $474-483$.

55. Nieminen TT, O'Donohue M-F, Wu Y, Lohi H, Scherer SW, Paterson AD et al. Germline mutation of RPS20, encoding a ribosomal protein, causes predisposition to hereditary nonpolyposis colorectal carcinoma without DNA mismatch repair deficiency. Gastroenterology 2014; 147: 595-598.e5.

56. Brighenti E, Calabrese C, Liguori G, Giannone FA, Treré D, Montanaro L et al. Interleukin 6 downregulates p53 expression and activity by stimulating ribosome biogenesis: a new pathway connecting inflammation to cancer. Oncogene 2014; 33: 4396-4406.

57. El Marjou F, Janssen KP, Chang BH, Li M, Hindie V, Chan L et al. Tissue-specific and inducible Cre-mediated recombination in the gut epithelium. Genesis 2004; 39: $186-193$.

58. Barker N, van Es JH, Kuipers J, Kujala P, van den Born M, Cozijnsen M et al. Identification of stem cells in small intestine and colon by marker gene Lgr5. Nature 2007; 449: 1003-1007.

59. Jacks T, Remington L, Williams BO, Schmitt EM, Halachmi S, Bronson RT et al. Tumor spectrum analysis in p53-mutant mice. Curr Biol 1994; 4: 1-7.

60. Guo J, Longshore S, Nair R, Warner BW. Retinoblastoma protein (pRb), but not p107 or p130, is required for maintenance of enterocyte quiescence and differentiation in small intestine. J Biol Chem 2009; 284: 134-140.

61. Léguillier T, Vandormael-Pournin S, Artus J, Houlard M, Picard C, Bernex F et al. Omcg1 is critically required for mitosis in rapidly dividing mouse intestinal progenitors and embryonic stem cells. Biol Open 2012; 1: 648-657.

62. O'Donohue M-F, Choesmel V, Faubladier M, Fichant G, Gleizes P-E. Functional dichotomy of ribosomal proteins during the synthesis of mammalian $40 \mathrm{~S}$ ribosomal subunits. J Cell Biol 2010; 190: 853-866.

63. Fichelson P, Moch C, Ivanovitch K, Martin C, Sidor CM, Lepesant J-A et al. Live-imaging of single stem cells within their niche reveals that a U3snoRNP component segregates asymmetrically and is required for self-renewal in Drosophila. Nat Cell Biol 2009; 11 : 685-693. 